Correction

\title{
Correction: Capocchi, A., et al. Overtourism: A Literature Review to Assess Implications and Future Perspectives. Sustainability 2019, 11, 3303
}

\author{
Alessandro Capocchi * , Cinzia Vallone, Mariarita Pierotti and Andrea Amaduzzi \\ Department of Business Economics and Law-DiSEADE, University of Milano Bicocca, Via Bicocca degli \\ Arcimboldi, 8, 20126 Milano, Italy; cinzia.vallone@unimib.it (C.V.); mariarita.pierotti@unimib.it (M.P.); \\ andrea.amaduzzi@unimib.it (A.A.) \\ * Correspondence: alessandro.capocchi@unimib.it; Tel.: +39-026-448-3191
}

Received: 18 November 2019; Accepted: 19 November 2019; Published: 19 February 2020

The authors would like to make the following corrections to the published paper [1]. The changes are as follows:

(1) Replacing the affiliation:

1 Department of Business Economics and Law-DiSEADE, University of Milano Bicocca, Via Bicocca degli Arcimboldi, 8, 20126 Milano, Italy

2 Department of Economic and Business Sciences and Right to the Economy, University of Milano Bicocca, Via Bicocca degli Arcimboldi, 8, 20126 Milano, Italy

with

Department of Business Economics and Law-DiSEADE, University of Milano Bicocca, Via Bicocca degli Arcimboldi, 8, 20126 Milano, Italy

(2) Replacing the descriptions in Section 3.2.1:

The authors observe too that the term first emerged in public discourse and describes phenomena that were discussed in the scholarly literature long before the term itself became commonly used, with the debate on the harmful effects of tourism going back to the 1960s.

with

The authors observe too that the term emerged for the first time in public debate regarding the phenomena discussed in the academic literature during the 1960s on the negative effects of tourism on destinations.

(3) Replacing the descriptions in Section 3.2.1:

Similarly, Benner [37] finds that, on a theoretical level, the recent debate regarding overtourism and, more generally, concerning the cultural, social and environmental sustainability deficits of permanently growing mass tourism is not new. What is new, though, is the level of awareness of the possibly damaging effects of the permanent quantitative growth of mass tourism. 
with

Similarly, Benner [37] (pp. 3-4) finds that, "on a theoretical level, the recent debate regarding overtourism and, more generally, concerning the cultural, social and environmental sustainability deficits of permanently growing mass tourism is not new. What is new, though, is the level of awareness of the possibly damaging effects of the permanent quantitative growth of mass tourism."

(4) Replacing the descriptions in Section 3.2.1:

For Benner [37], the potential risks connected to overtourism could include (a) rising costs of living and housing and real estate speculation that might eventually bring about gentrification and congestion of transport infrastructures; (b) a deterioration of local residents' identification with place; (c) the loss of a destination's authentic character, or substantial harm to its cultural or environmental heritage or (d) the privatization of spaces that are supposed to be publicly accessible-and hence segregation ([6] (pp. 2-4), [22] (p. 375)).

with

For Benner ([37] (p. 6)), the potential risks connected to overtourism could include (a) increasing costs of living; (b) real estate speculation; (c) congestion of transport infrastructures; (d) the loss of sense of belonging of local residents with the place; (e) the loss of a destination's authentic character or (f) the privatization of spaces ([6] (pp. 2-4), [22] (p. 375)).

(5) Replacing the descriptions in Section 3.2.1:

"Looking back to past decades since the early 1970s, it seems reasonable to infer that former consensus on the desirability of quantitative, resource-intense and therefore unsustainable growth in manufacturing has broken down in the wake of the "limits to growth" debate".

with

“Looking back to past decades since the early 1970s, it seems reasonable to infer that former consensus on the desirability of quantitative, resource-intense and therefore unsustainable growth in manufacturing has broken down in the wake of the 'limits to growth' debate" ([37] (p. 6)).

(6) Replacing the descriptions in Section 3.2.1:

For Benner [37], the current public debate on overtourism could play a similar role to that of the Club of Rome's 1972 report and the discussions that commenced in its aftermath. Certainly, in leading tourist destinations marked by the harmful effects of overtourism, any previous consensus on the desirability of permanent quantitative tourism growth for the sake of maximizing the economic benefits of tourism without fully considering the possibly damaging side effects on the social, cultural and ecological environments has come under intense pressure from civil society and local populations. To safeguard the economic benefits of tourism, shifting the focus of tourism development toward qualitative growth and drawing on market segments with higher localized value added and lower social, cultural and environmental impact will be necessary to balance the economic effects desired, such as generating localized value added, tax revenues, and employment, with the social, cultural and environmental sustainability that is indispensable in the long term.

with

For Benner ([37] (pp. 6-7)), "the current public debate on overtourism could play a similar role to that of the Club of Rome's 1972 report and the discussions that commenced in its aftermath. Certainly, in leading tourist destinations marked by the harmful effects of overtourism, any 
previous consensus on the desirability of permanent quantitative tourism growth for the sake of maximizing the economic benefits of tourism without fully considering the possibly damaging side effects on the social, cultural and ecological environments has come under intense pressure from civil society and local populations. To safeguard the economic benefits of tourism, shifting the focus of tourism development toward qualitative growth and drawing on market segments with higher localized value added and lower social, cultural and environmental impact will be necessary to balance the economic effects desired, such as generating localized value added, tax revenues, and employment, with the social, cultural and environmental sustainability that is indispensable in the long term".

(7) Replacing the descriptions in Section 3.2.3:

Due to the ecological sensitivity of the lagoon, the old city and its immediate surroundings represent an ecosystem very much endangered not only by increasing crowds of visitors but also by the type of tourism prevalent—notably, cruise ships crossing the lagoon [22].

with

"Due to the ecological sensitivity of the lagoon, the old city and its immediate surroundings represent an ecosystem very much endangered not only by increasing crowds of visitors but also by the type of tourism prevalent—notably, cruise ships crossing the lagoon" ([22], [37] (p. 5)).

(8) Replacing the descriptions in Section 3.2.3:

The Croatian coastal city of Dubrovnik is another salient example pertaining to the damaging effects and problems related to overtourism on the Adriatic Sea. Due to the popularity of its old town, the boom of cruise tourism, and the impact of the widely known television series Game of Thrones being shot partly in Dubrovnik, a quantitative growth in tourism has led to overcrowding and to what Panayiotopoulos and Pisano [73] (p. 7) call an "overtourism dystopia" related to "the paradox of tourism risking to destroy the very thing that tourists come to see." Policy responses have included attempts to limit the number of tourists admitted to the city and to restrict the capacity of cruise ships permitted to call at the city's port [73].

with

“The Croatian coastal city of Dubrovnik is another salient example pertaining to the damaging effects and problems related to overtourism on the Adriatic Sea. Due to the popularity of its old town, the boom of cruise tourism, and the impact of the widely known television series Game of Thrones being shot partly in Dubrovnik, a quantitative growth in tourism has led to overcrowding and to what Panayiotopoulos and Pisano [73] (p. 7) call an "overtourism dystopia" related to "the paradox of tourism risking to destroy the very thing that tourists come to see." Policy responses have included attempts to limit the number of tourists admitted to the city and to restrict the capacity of cruise ships permitted to call at the city's port" ([37] (pp. 5-6)) [73].

(9) Replacing the descriptions in Section 3.3:

Benner [37] discusses overtourism as a complex and multilayered phenomenon specific to the context at hand [8], countering that it is necessarily a multidimensional effort that can be analyzed along the dimensions of policies, organizations, institutions, and behavior.

with

Benner ([37] (p. 7)) discusses overtourism as "a complex and multilayered phenomenon specific to the context at hand [8], countering that it is necessarily a multidimensional effort that can be analyzed along the dimensions of policies, organizations, institutions, and behavior." 
The authors and the Editorial Office would like to apologize for any inconvenience caused to the readers by these changes. The changes do not affect the scientific results. The manuscript will be updated and the original will remain online on the article webpage.

\section{Reference}

1. Capocchi, A.; Vallone, C.; Pierotti, M.; Amaduzzi, A. Overtourism: A Literature Review to Assess Implications and Future Perspectives. Sustainability 2019, 11, 3303. [CrossRef]

(C) 2020 by the authors. Licensee MDPI, Basel, Switzerland. This article is an open access article distributed under the terms and conditions of the Creative Commons Attribution (CC BY) license (http://creativecommons.org/licenses/by/4.0/). 